\title{
Co-morbidity and treatment of attention deficit hyperactivity disorder in Saudi Arabia
}

F.A. Al-Haidar ${ }^{1}$

$$
\begin{aligned}
& \text { معالجة اضطراب نقص الانتباه وفرط الحر كة والأمر اض المصاحبة في المملكة العربية السعودية }
\end{aligned}
$$

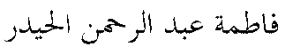

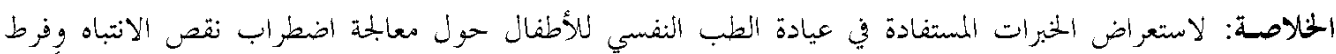

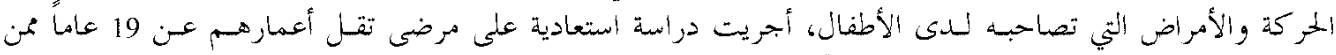

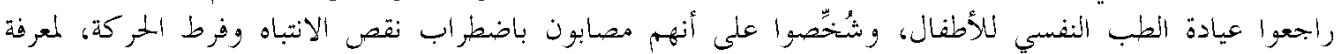

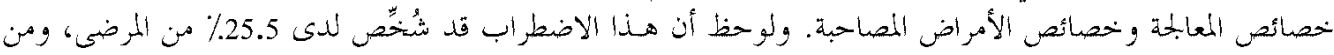

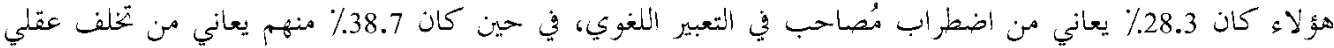

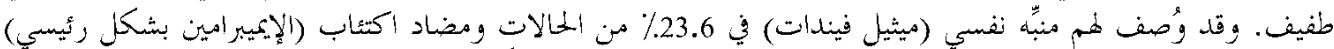

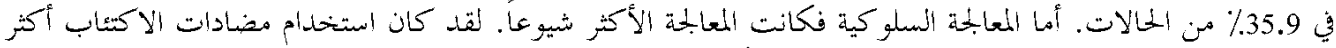

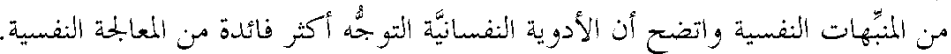

ABSTRACT To review the experience of a child psychiatric clinic regarding co-morbidity and treatment characteristics of children with attention deficit hyperactivity disorder (ADHD), a retrospective study was done on patients under 19 years who were attending the clinic and were diagnosed with ADHD. Co-morbidity and treatment characteristics were also studied. ADHD was diagnosed in $25.5 \%$ of the patients. Of these, $28.3 \%$ had coexistent expressive language disorder and $38.7 \%$ coexistent mild mental retardation. A psychostimulant (methylphenidate) was prescribed to $23.6 \%$ while antidepressants (primarily imipramine) were prescribed to $35.9 \%$. Behavioural therapy was the most commonly offered psychotherapy. Antidepressants were used more than psychostimulants. Psychotropics had a more beneficial effect than psychotherapy.

Comorbidité et traitement du trouble d'hyperactivité avec déficit de l'attention en Arabie saoudite RESUME Afin d'examiner l'expérience d'une clinique de pédopsychiatrie en ce qui concerne la comorbidité et les caractéristiques du traitement des enfants souffrant d'hyperactivité avec déficit de l'attention (HADA), une étude rétrospective a été réalisée auprès des patients de moins de 19 ans qui consultaient à la clinique et chez lesquels un diagnostic de HADA avait été posé. La comorbidité et les caractéristiques du traitement ont également été étudiées. Une hyperactivité avec déficit de l'attention a été diagnostiquée chez $25,5 \%$ des patients. Parmi ces patients, 28,3\% avaient des troubles expressifs du langage coexistants et 38,7\% avaient une légère arriération mentale coexistante. Un psychostimulant (méthylphénidate) a été prescrit à $23,6 \%$ des patients tandis que des antidépresseurs (principalement l'imipramine) ont été prescrits à 35,9\%. La thérapie comportementale était la psychothérapie la plus fréquemment offerte. Les antidépresseurs étaient davantage utilisés que les psychostimulants et les psychotropes ont montré un effet plus bénéfique que la psychothérapie.

${ }^{1}$ Department of Psychiatry, King Khalid University Hospital, Riyadh, Saudi Arabia. Received: 21/11/02; accepted: 22/04/03 


\section{Introduction}

Attention deficit hyperactivity disorder (ADHD) is a disorder of childhood and adolescence characterized by a pattern of extreme pervasive, persistent and debilitating inattention, overactivity and impulsivity [1]. It is believed to be one of the most common reasons for mental health referrals to family physicians, paediatricians, paediatric neurologists and child and adolescent psychiatrists [2,3].

Although originally thought to remit during childhood, the symptoms of ADHD have also been shown to persist in patients through adolescence and into adulthood [4]. The disorder is often chronic, with one third to one half of those affected retaining the condition into adulthood [5-7].

It interferes with many areas of normal development and functioning in a child's life [2]. Children with ADHD are more likely than their peers to experience educational underachievement, social isolation and antisocial behaviour during the school years [8] and to go on to have significant difficulties in the post-school years $[9,10]$.

The aim of this study is to review the experience of a child psychiatric clinic regarding co-morbidity and treatment characteristics of children with ADHD. Evaluating our current clinical experience with ADHD and comparing it with others will allow us to offer better service to our patients in the future.

\section{Methods}

The case records of all patients (416) up to 18 years of age who attended the child psychiatric outpatient clinic at King Khalid University Hospital, Riyadh, Saudi Arabia over a period of 10 years (July 1990 to July 2000) were examined. Those who were diagnosed as having ADHD (106) were re- trospectively reviewed with regard to comorbidity, prescribed psychotropic medication and type of psychotherapy offered.

The diagnosis of ADHD and co-morbid disorders was based on the Diagnostic statistical manual of mental disorders [1].

The psychological tests used to determine the degree of mental retardation included the Wechsler Intelligence Scale for Children, the Stanford-Binet Intelligence Scale and the Vinland Adaptive Behavioral Scale.

Psychotherapy offered included behavioural therapy and family counselling. In behavioural therapy, parents were given strategies to modify their children's behaviour (e.g. point/token reward system and time-out). In family counselling, parents had the opportunity to establish a positive relationship within the family and relieve guilt feelings through an external attribution of the cause and difficulties.

\section{Results}

Case records of 416 patients were reviewed; 106 (25.5\%) were diagnosed as having ADHD, either as the only diagnosis, $53(12.7 \%)$, or in combination with other psychiatric disorders, 53 (12.7\%).

Demographic data are shown in Table 1. Boys accounted for $77.4 \%$ and girls $22.6 \%$, a ratio of 3.4 males to 1 female. Adolescents accounted for only $3.7 \%$ of the boys and none of the girls.

The majority (93.4\%) of the group were Saudi Arabian nationals. Most of the patients had not attended school (63.2\%), while $30.2 \%$ had had some sort of education that varied from kindergarten to high school, and $6.6 \%$ were attending a special school for children with mental disabilities.

Table 2 lists the co-morbid psychiatric disorders. Half of the sample (53.0\%) did

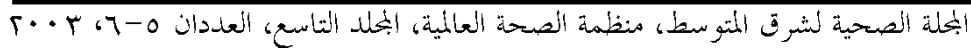




\begin{tabular}{|c|c|c|c|}
\hline Variable & $\begin{array}{c}0-12 \text { years } \\
(n=103) \\
\text { No. }(\%)\end{array}$ & $\begin{array}{c}\text { 13-18 years } \\
(n=3) \\
\text { No. }(\%)\end{array}$ & $\begin{array}{c}\text { Total }(n=106) \\
\text { No. }(\%)\end{array}$ \\
\hline \multicolumn{4}{|l|}{ Sex } \\
\hline Male & $79(76.7)$ & $3(100.0)$ & $82(77.4)$ \\
\hline Female & $24(76.7)$ & $0(0.0)$ & $24(22.6)$ \\
\hline \multicolumn{4}{|l|}{ Nationality } \\
\hline Saudi Arabian & $96(93.2)$ & $3(100.0)$ & 99 (93.4) \\
\hline Non-Saudi Arabian & $7(6.8)$ & $0(0.0)$ & $7(6.6)$ \\
\hline \multicolumn{4}{|l|}{ Education } \\
\hline Not educated & $67(65.0)$ & $0(0.0)$ & $67(63.2)$ \\
\hline Educated & $29(28.2)$ & $3(100.0)$ & $32(30.2)$ \\
\hline $\begin{array}{l}\text { School for children with } \\
\text { mental disability }\end{array}$ & $7(6.8)$ & $0(0.0)$ & $7(6.6)$ \\
\hline
\end{tabular}

not show any co-morbid psychiatric disorder, the commonest associated disorder was expressive language disorder (28.3\%) followed by nocturnal enuresis (10.4\%).

A review of the co-morbidity of ADHD and mental retardation shows that nearly half of the sample (47.2\%) did not show any degree of mental retardation while

\begin{tabular}{lcc}
\hline $\begin{array}{l}\text { Table } 2 \text { Attention deficit hyperactivity } \\
\text { disorder and co-morbid psychiatric } \\
\text { diagnosis }\end{array}$ \\
\hline Diagnosis & No. $(\boldsymbol{n}=\mathbf{1 0 6})$ & $\%$ \\
\hline None & 53 & 50.0 \\
Expressive language & & \\
$\quad$ disorder (ELD) & 30 & 28.3 \\
Nocturnal enuresis (NE) & 11 & 10.4 \\
ELD + NE & 5 & 4.7 \\
ELD + NE + encopresis & 4 & 3.8 \\
NE + encopresis & 2 & 1.9 \\
Stuttering & 1 & 0.9 \\
\hline
\end{tabular}

$38.7 \%$ had mild, $12.3 \%$ had moderate and $1.9 \%$ had severe mental retardation.

The prescribed psychotropic medications are listed in Table 3. Methylphenidate was the only psychostimulant given and was the most commonly prescribed drug. Imipramine was the most commonly prescribed antidepressant and the second most commonly prescribed psychotropic. Haloperidol was the most commonly prescribed antipsychotic and the third most commonly prescribed psychotropic. Only $6.6 \%$ of the group did not receive any form of medication.

The duration of medication use varied from 1 month to 60 months, with a mean of 17 months. Regular follow-ups were performed in $34.0 \%$ of patients, while $66.0 \%$ had irregular follow-ups. There was no significant report of side-effects that we could use for analysis.

Behavioural therapy was the most commonly offered type of psychotherapy (44 patients, $46.2 \%)$. Only 4 patients (3.8\%) had family counselling, 9 patients (8.5\%) 


\begin{tabular}{lccr}
\hline \multicolumn{3}{l}{$\begin{array}{l}\text { Table 3 Attention deficit hyperactivity disorder and } \\
\text { prescribed psychotropic medications }\end{array}$} \\
\hline Type of drug & Drug & No. $(\boldsymbol{n}=\mathbf{1 0 6})$ & $\%$ \\
\hline Stimulants & Methylphenidate & 25 & 23.6 \\
Antidepressants & Imipramine & 23 & 21.7 \\
& Amitriptyline & 4 & 3.8 \\
& Fluoxetine & 6 & 5.7 \\
& Citalopram & 4 & 3.8 \\
& Paroxetine & 1 & 0.9 \\
Antipsychotics & Haloperidol & 17 & 16.0 \\
& Zuclopentixol & 4 & 3.8 \\
& Thioridazine & 9 & 8.5 \\
& Trifluperazine & 2 & 1.9 \\
& Risperidone & 1 & 0.9 \\
Anticonvulsants & Carbamazepine & 2 & 1.9 \\
& Sodium valproate & 1 & 0.9 \\
None & None & 7 & 6.6
\end{tabular}

had both therapies and 44 (41.5\%) did not receive any formal psychotherapy.

Table 4 shows a comparison of the outcome for those patients who received psychotropic drugs, psychotherapy or both (assessment of the outcome was based only on the reported information in the clinical records). All 106 patients received some sort of intervention; the majority (52.8\%) received both, while $38.7 \%$ received drugs only and $8.5 \%$ received psychotherapy alone. Among those who showed improvement, predominantly this was only partial improvement. Patients who received drugs showed the greatest improvement, while those who received both drugs and psychotherapy mostly showed partial improvement. Those who received psychotherapy alone did not show much improvement.

\section{Discussion}

The common heterogeneous disorder ADHD is conservatively estimated to affect $3 \%-5 \%$ of school-age children [11]. When the diagnosis of ADHD is made with standardized structured interview to parents or teachers however, then the prevalence has been reported as reaching $19 \%$ in primary school age boys [12], with a much higher prevalence (30\% to $50 \%$ ) in those attending child and adolescent psychiatric outpatient clinics [1,13]. This study was conducted in an outpatient psychiatric clinic, so a prevalence of $25.5 \%$ is in agreement with the results of previous studies of samples from similar populations.

In one study conducted in the United States of America (USA) using DSM IV, $22 \%-40 \%$ of referred children were diag-

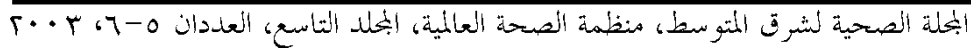




\begin{tabular}{lrrrrrrrrr}
\hline \multicolumn{1}{l}{ Table 4 Outcome in relation to prescribed drugs and type of psychotherapy conducted } \\
\hline & \multicolumn{1}{c}{ Poor } & Partial & $\begin{array}{c}\text { Outcome } \\
\text { Remarkable }\end{array}$ & Not known & $\begin{array}{c}\text { Total } \\
(\boldsymbol{n}=106)\end{array}$ \\
& No. & $\%$ & No. & $\%$ & No. & $\%$ & No. & $\%$ & $\%$ \\
\hline Drugs $(n=41)$ & 5 & 12.2 & 15 & 36.6 & 17 & 41.5 & 4 & 9.8 & 38.7 \\
Psychotherapy $(n=9)$ & 3 & 33.3 & 2 & 22.2 & 1 & 11.1 & 3 & 33.3 & 8.5 \\
Both $(n=56)$ & 11 & 17.9 & 22 & 39.3 & 12 & 21.4 & 11 & 19.6 & 52.8 \\
Total $(n=106)$ & 19 & 17.9 & 39 & 36.8 & 30 & 28.3 & 18 & 17.0 & 100.0
\end{tabular}

All patients received some intervention.

nosed as having ADHD [10], compared to $1.2 \%$ in the United Kingdom which used the International Classification of mental and behavioural disorders, tenth edition (ICD 10) [14]. So the findings of our study (25.5\%) correspond with the USA studies, explained at least partially by the employment of the same diagnostic measures, DSM III-R or DSM IV.

Although community-based studies have found male to female sex ratio for ADHD as low as 2.1:1, male to female ratio in referred samples (similar to this study sample) ranged from 4:1 to 9:1 [1,15], comparable to the findings of this study (3.4:1).

There are several reasons for the greater vulnerability of boys. Adults are often more tolerant of hyperactivity in girls than in boys, at least before school age [16]. Also, compared with boys, girls with ADHD tend to have greater intellectual impairment and inattention, lower levels of hyperactivity and lower rates of conduct behaviour [17-20].

Attention deficit hyperactivity disorder is quite strongly associated with a range of abnormalities in psychological and motor development [14]. The typical abnormalities found are immature articulation and language delay [21].
Some of the sample (20.8\%) were diagnosed to have enuresis and/or encopresis.This association may be related to delayed toilet training due to difficulty in learning because of inattention and hyperactivity, or related to associated mental retardation.

The association between ADHD and conduct disorder is so great that some reviewers consider that hyperactivity and conduct disorder are actually the same problem under different names [22-24]. However in this study, an association between ADHD and conduct disorder was not detected. Because conduct disorder is primarily a behavioural disturbance, the family and the community in general may perceive it as misbehaviour rather than a psychiatric disorder and may deal with it themselves, in which case children exhibiting this type of behaviour will not be referred to a psychiatric unit.

ADHD is associated with reduced verbal and performance intelligence [24]. In a study of mild mental retardation, ADHD accounted for $10 \%-14 \%$ of the whole group [24]. Some investigators have reported that as many as a quarter to one third of those with severe mental retardation manifest co-morbid hyperactivity 
$[24,25]$. Other studies showed that as the mental retardation becomes more severe, the association with ADHD is more expected [26]. In this study, however, a greater association with mild mental retardation was found. This may be because the more severely retarded patients are dealt with by the institutes for the mentally retarded and rehabilitation centres, where they have their own psychologists and psychiatrists who rarely refer to other centres for psychiatric assessment or management.

A wide variety of treatments have been used for ADHD including, but not limited to, various psychotropic medications, psychosocial interventions, dietary management, training and educational programmes [27]. Psychostimulants such as methylphenidate, amphetamine, dextroamphetamine and pemoline are prescribed for about two thirds of children with ADHD $[28,29]$, methylphenidate being the most often used $[27,30]$. Methylphenidate was the only psychostimulant prescribed in this study and was prescribed less (23.6\%) compared to other studies [30,31].

The value of antidepressants in the treatment of ADHD, particularly imipramine, has been reported in several circumstances such as the coexistence of emotional disorders, failure to respond to psychostimulants and coexistence of tics $[2,25]$. Overall in this study, antidepressants (35.9\%) were more often prescribed than psychostimulants (23.6\%). This contrasts with the findings of other studies $[27,28]$.
However, in accordance with the findings of other studies, haloperidol was the most commonly prescribed antipsychotic, and carbamazepine the most commonly prescribed mood stabilizer [2]. Haloperidol has been reported to be useful for those hyperactive children with Tourette's syndrome or tics [2]. Mood stabilizers, particularly carbamazepine and sodium valproate, do not seem to have a positive effect on core ADHD symptoms, however, they have been reported to be useful in controlling behaviour disturbance and aggression [2].

The finding of this study that behavioural therapy is used more than family counselling has been reported before [25]. However, both interventions have been found to be useful for many hyperactive children [25,27].

Comparing the beneficial effects of psychotropics and psychotherapy, the results of this study supported the superiority of psychotropics, a finding in agreement with previous reports [27]. In this study as well as others, combining psychotropics and behavioural therapy added little advantage overall over medication alone [27].

\section{Acknowledgement}

I wish to thank sincerely Mr Wendel Cuyos for his secretarial work.

\section{References}

1. Diagnostic and statistical manual of mental disorders, 4th ed. Washington, DC, American Psychiatric Association, 1994.

2. Cantwell DP. Attention deficit disorder: a review of the past 10 years. Journal of the American Academy of Child and Adolescent Psychiatry, 1996, 35:97887.

3. Biederman J, Newcorn J, Sprich S. Comorbidity of attention deficit hyperactivity disorder with conduct, depressive,

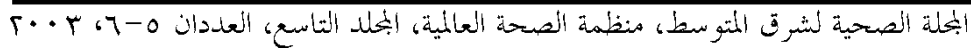


anxiety and other disorders. American journal of psychiatry, 1991, 148:564-77.

4. Hechtman L. Long-term outcome in attention deficit hyperactivity disorder. Child and adolescent psychiatric clinics of North America, 1992, 1:553-65.

5. Lambert NM. Adolescent outcomes for hyperactive children. Perspectives on general and specific patterns of childhood risk for adolescent educational, social, and mental health problems. American psychologist, 1988, 43:78699.

6. Mannuzza S et al. Hyperactive boys almost grown up. V. Replication of psychiatric status. Archives of general psychiatry, 1991, 48:77-83.

7. Weiss $\mathrm{G}$ et al. T. Psychiatric status of hyperactives as adults: a controlled prospective 15-year follow-up of 63 hyperactive children. Journal of the American Academy of Child and Adolescent Psychiatry, 1985, 24:211-20.

8. Biederman J, Faraone S, Milberger S. A prospective 4 year follow-up study of attention-deficit hyperactivity and related disorders. Archives of general psychiatry, 1996, 53:437-46.

9. Lynam DR. Early identification of chronic offenders: who is the fledgling psychopath? Psychological bulletin, 1996, 120: 209-34.

10. Mannuzza $S$ et al. Adult psychiatric status of hyperactive boys grown up. American journal of psychiatry, 1998, 155: 493-8.

11. Shaffer $D$ et al. The NIMH diagnostic interview schedule for children version 2.3 (DISC-2.3): description, acceptability, prevalence rates, and performance in the MECA study. Methods for the epidemiology of child and adolescent mental disorders study. Journal of the American Academy of Child and Adolescent Psychiatry, 1996, 35:865-77.
12. Shekim W et al. The prevalence of attention deficit disorders in a rural midwestern community sample of nineyear-old children. Journal of the American Academy of Child and Adolescent Psychiatry, 1985, 24:765-70.

13. Zarin DA et al. Clinical and treatment characteristics of children with attentiondeficit/hyperactivity disorder in psychiatric practice. Journal of the American Academy of Child and Adolescent Psychiatry, 1998, 37:1262-70.

14. Taylor EA. Childhood hyperactivity. British journal of psychiatry, 1986, 49:562573.

15. Szatmari P. The epidemiology of attention deficit hyperactivity disorder. Child and adolescent psychiatric clinics of North America, 1992, 1:361-71.

16. Battle ES, Lacey B. A context for hyperactivity in children, over time. Child development, 1972, 43:757-73.

17. Gaub M, Carlson CL. Gender differences in ADHD: a meta-analysis and critical review. Journal of the American Academy of Child and Adolescent Psychiatry, 1997, 36:1036-46.

18. Safer DJ, Krager JM. A survey of medication treatment for hyperactive/inattentive students. Journal of the American Medical Association, 1988, 260:2256-8.

19. Wilens T, Biederman J. The stimulants. Psychiatric clinics of North America, 1992, 15:191-222.

20. Berry CA, Shaywitz SE, Shaywitz BA. Girls with attention deficit disorder: a silent minority? A report on behavioral and cognitive characteristics. Pediatrics, 1985, 76:801-9.

21. Reeves JE et al. Attention deficit, conduct, oppositional and anxiety disorders in children: II. Clinical characteristics. Journal of the American Academy of 
Child and Adolescent Psychiatry, 1987, 26: 144-55.

22. Shaffer D, Greenhill L. A critical note on the predictive validity of "the hyperkinetic syndrome". Journal of child psychology and psychiatry, 1979, 20:61-72.

23. Prior M, Sanson A. Attention deficit disorder with hyperactivity: a critique. Journal of child psychology and psychiatry, 1988, 27:307-19.

24. Bird H, Gould M, Staghezza-Jaramillo B. The comorbidity of ADHD in a community sample of children aged 6 through 16 years. Journal of child and family studies, 1994, 3:365-78.

25. Taylor E. Syndromes of attention deficit and overactivity. In: Rutter M, Taylor E, Hersov L, eds. Child and adolescent psychiatry, 3rd ed. London, Blackwell Science, 1994:285-307.

26. Gillberg $\mathrm{C}$ et al. Psychiatric disorder in mildly and severely mentally retarded urban children and adolescents: epidemiological aspects. British journal of psychiatry, 1986, 149:68-74.

27. National Institutes of Health Consensus Development Conference Statement: di- agnosis and treatment of attention-deficit/hyperactivity disorder (ADHD). Journal of the American Academy of Child and Adolescent Psychiatry, 2000, 39:182-93.

28. James RS et al. Double-blind placebocontrolled study of single-dose amphetamine formulation in ADHD. Journal of the American Academy of Child and Adolescent Psychiatry, 2001, 40:126876.

29. Hoagwood $\mathrm{K}$ et al. Treatment services for children with ADHD: a national perspective. Journal of the American Academy of Child and Adolescent Psychiatry, 2000, 39:198-206.

30. Swanson J et al. Effect of stimulant medication on children with attention deficit disorder: a "review of reviews". Exceptional children, 1993, 60:154-62.

31. Spencer T et al. Pharmacotherapy of attention-deficit hyperactivity disorder across the life cycle. Journal of the American Academy of Child and Adolescent Psychiatry, 1996, 35:409-32.

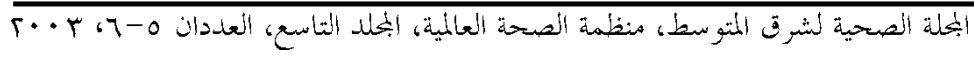

